\title{
Scientific Conference with international participation "Dynamic Processes in the Chemistry of Organoelement Compounds" dedicated to the 115th anniversary of the birth of Academician B. A. Arbuzov (November 6-9, 2018, Kazan)
}

The scientific Conference with international participation "Dynamic Processes in the Chemistry of Organoelement Compounds" dedicated to the 115th anniversary of the birth of Academician B. A. Arbuzov will be held on November 6-9, 2018, in Kazan.

\author{
Organizers \\ Russian Academy of Sciences (RAS) \\ Federal Agency of Scientific Organizations \\ Federal Research Center "Kazan Scientific Center of the Russian Academy of Sciences" \\ A. E. Arbuzov Institute of Organic and Physical Chemistry \\ Russian Foundation for Basic Research \\ D. I. Mendeleev Republican Chemical Society \\ Chairman of the Conference Academician of RAS O. G. Sinyashin

\section{Program Committee} \\ Chairman \\ Corr. Member of RAS A. I. Antipin \\ Professor Yu. G. Budnikova \\ Professor A. A. Bredikhin \\ Professor A. R. Burilov \\ Professor V. I. Galkin \\ Corr. Member of RAS Yu. G. Gorbunova \\ Academician of RAS M. P. Egorov \\ Academician of RAS I. L. Eremenko \\ Academician of RAS A. I. Konovalov \\ Professor A. A. Karasik (Kazan) \\ Corr. Member of RAS V. Yu. Kukushkin \\ Corr. Member of RAS V. F. Mironov \\ Academician of RAS A. M. Muzafarov \\ Academician of RAS V. I. Ovcharenko \\ Professor A. A. Trifonov \\ Professor Yu. G. Trishin \\ Corr. Member of RAS V. P. Fedin \\ Corr. Member of RAS I. L. Fedyushkin \\ Professor D. G. Yakhvarov
}

Organizing Committee

Chairman Professor A. A. Karasik (Kazan)
O. A. Andreeva
A. A. Zagidullin
A. V. Nemtarev
N. R. Khasiyatullina
M. G. Belenok
A. V. Bogdanov
A. I. Karasik
A. V. Smolobochkin
M. N. Khrizanforov
A. S. Gazizov
T. D. Keshner
I. D. Strel'nik
R. R. Sharipova
O. E. Naumova
D. A. Tatarinov
A. M. Yakupov

\section{Scientific Program}

The program of the Conference covers a broad range of relevant fundamental and applied subjects in organoelement chemistry including novel reagents and methods in organoelement synthesis; supramolecular and coordination chemistry of organoelement compounds; quantum chemical approaches to the description of processes in organoelement compounds; tautomerism and isomerism of organoelement compounds; materials based on organoelement compounds; physical methods for studying the dynamic processes of organoelement compounds in solutions and crystals; and organoelement compounds in living systems.

The scientific program of the Conference includes plenary and oral reports and posters. The working languages of the Conference are Russian and English.

\section{Organizing Secretariat}

For all organizational issues, please address Anzhelika Igorevna Karasik, Conference Secretary.

Phone.: +7 (843) 272 7424. E-mail: arbuzov2018@iopc.ru. 